\section{High genetic diversity despite drastic bottleneck in a critically endangered, long-lived seabird, the Mascarene Petrel Pseudobulweria aterrima} JADE LOPEZ,*1 (D) NATACHA NIKOLIC, ${ }^{2}$ MARTIN RIETHMULLER, ${ }^{3}$ JÉRÔME DUBOS, ${ }^{1,4}$ PATRICK PINET ${ }^{4}$ PATXI SOUHARCE, ${ }^{5}$ FRANÇOIS-XAVIER COUZI, ${ }^{3}$ MATTHIEU LE CORRE, ${ }^{1}$ AUDREY JAEGER ${ }^{1}$ \& LAURENCE HUMEAU ${ }^{6}$

${ }^{1}$ UMR ENTROPIE, Université de La Réunion, 15 Avenue René Cassin, CS 92003, Saint Denis Cedex 9 , Reunion Island, 97744, France

${ }^{2}$ ARBRE (Agence de Recherche pour la Biodiversité à la Réunion), 18 Rue des Seychelles, Saint-Leu,

Reunion Island, 97436, France

${ }^{3}$ Société d'Etudes Ornithologiques de La Réunion, 13 Ruelle des Orchidées Cambuston, Saint André, Reunion Island, 97440, France

${ }^{4}$ Parc national de La Réunion, Life+ Pétrels, 258 Rue de la République, Plaine des Palmistes, Reunion Island, 97431, France

${ }^{5}$ Office national de la chasse et de la faune sauvage, Brigade nature de l'océan Indien, Saint-Denis, Reunion Island, 97400, France

${ }^{6}$ UMR PVBMT, Université de La Réunion, 15 Avenue René Cassin, CS 92003, Saint Denis Cedex 9 , Reunion Island, 97744, France

The Mascarene Petrel Pseudobulweria aterrima is a criti cally endangered seabird endemic to Reunion Island, with an extremely small population suffering several threats. Fifteen polymorphic microsatellite loci were iso lated from this species to analyse genetic diversity, esti mate contemporary effective population size, search for evidence of a population bottleneck and see whether results support the hypothesis that life history traits could preserve allelic diversity in small populations. Results from 22 individuals found grounded as a conse quence of light pollution highlight a surprisingly high genetic diversity, an absence of inbreeding, a contempo rary effective population size estimated at approximately

*Corresponding author.

Email: jadelopez84@hotmail.fr
1211 individuals and a probable bottleneck around 10000 generations ago. Additional studies on genetic diversity and structure from a larger number of samples are thus required to evaluate the evolutionary potential of this critically endangered species.

Keywords: conservation, decreased population size, evolutionary potential, microsatellite markers, rare species.

Seabirds are the most threatened birds in the world, with about $28 \%$ of species considered endangered (Croxall et al. 2012). Among seabirds, tropical petrels (genera Pterodroma and Pseudobulweria) are among the least known and most vulnerable (Croxall et al. 2012), with the two main threats being predation by intro duced mammals (Keitt et al. 2002, Le Corre 2008) and light pollution, especially for young birds (Rodriguez et al. 2017). These threats may lead to local extinctions of some populations (Croxall et al. 2012, Dias et al. 2019).

Pseudobulweria, comprising four species, is the least known genus of Procellariidae (Warham 1990). Among them, the Mascarene Petrel Pseudobulweria aterrima, endemic to Reunion Island, is the only representative of the genus in the Indian Ocean. This species is listed as Critically Endangered due to an extremely small breed ing population $(\sim 100200$ mature individuals $)$ and a presumed continuing decline related to predation and light induced mortality (Birdlife International 2018). With the prominent exception of a seabird rescue cam paign initiated in 1997 by a local non governmental organization (Société d'Etudes Ornithologiques de La Réunion SEOR, Le Corre et al. 2003), research and conservation actions focused on Mascarene Petrels effec tively started in 2015 with the implementation of the European LIFE + Pétrels project. Given the recency of research efforts, the ecology and biology of this species are still poorly known.

Endangered species typically have small and decreas ing population sizes and low genetic variability, espe cially when compared with closely related taxa that are not threatened (Ardern \& Lambert 1997, Spielman et al. 2004). In small populations, theory also predicts a loss of genetic variability due to genetic drift and possi ble inbreeding depression (Nei et al. 1975). This is a major concern in conservation biology, as the loss of genetic variability may result in reduced survival, reduced fertility and increased susceptibility to diseases (Frankel \& Soulé 1981, Frankham et al. 2002). Many models and concepts on the loss of genetic diversity are based only or mainly on genetic drift and mutation (e.g. Lande 1995). In a small population, genetic drift no longer has an effect on the loss of diversity, and it is 
demographic and environmental stochasticity that pre vail (Lynch \& Gabriel 1990, Lynch \& Lande 1998, Masel 2012). Species life history traits may influence the rate of genetic variability decrease (Lippé et al. 2006). For example, the loss of genetic diversity could be slo wed down in monogamous species (Kuo \& Janzen 2004, Weiser et al. 2013). Monogamous breeding will retain genetic diversity more effectively than situations that allow mate choice or intrasexual competition (Gooley et al. 2018). Long generation time and overlapping gen erations could also reduce genetic loss. Multiple repro ductive outputs in long lived species result in higher genetic contribution to subsequent generations com pared with one or few reproductive outputs. When a population passes through a bottleneck, reduction of genetic diversity depends on population size and time, measured in number of generations (Hailer et al. 2006). Overlapping generations, often associated with a long generation time, thus reduce the loss of genetic diversity by allowing multiple cohorts simultaneously to be part of a genetic pool.

The Mascarene Petrel is a primarily monogamous and long lived species with delayed sexual maturity (Schreiber \& Burger 2001) and an estimated genera tion time of 17.7 years according to Birdlife Interna tional. Thus, we can expect that the loss of genetic diversity is less important than expected in this species even if it has a small population size. The objective of this study was to conduct a first assessment of the evolutionary potential of Mascarene Petrels, thereby informing future conservation measures and to see whether the results support the hypothesis that life history traits could preserve allelic diversity in small populations. We identified and characterized polymor phic microsatellite loci in order to investigate: (1) genetic diversity and inbreeding, (2) contemporary effective population size and (3) a potential popula tion bottleneck in this species.

\section{METHODS}

Total genomic DNA was extracted from whole blood samples of 22 Mascarene Petrels found grounded during the seabird rescue campaign on Reunion Island from 2008 to 2018. Blood samples were stored in 70\% etha nol, and DNA was then extracted with the QIAmp Blood \& Tissue kit (Qiagen).

A genomic library was constructed using DNA of one bird. Fifteen microsatellite sequences were isolated by Ecogenics GmbH (Zurich, Switzerland; Data S1).

A 3 primer PCR approach using an M13 tail (5' CACGACGTTGTAAAACGAC 3') for the forward pri mer was used for microsatellite loci amplification of DNA from all 22 birds, following Schuelke (2000). Four different dyes (6 FAM, PET, VIC, NED) were used for the universal M13 forward primer to enable fragment analysis multiplexing. Simplex PCR amplifications, tar geting one locus at a time, were performed using a Gen eAmp PCR System 9700 (Applied Biosystems) in a 10 $\mu \mathrm{L}$ reaction volume containing $5 \mu \mathrm{L}$ of MasterMix Applied 2x (Applied Biosystems), $0.025 \mu \mathrm{M}$ of the for ward primer with M13 5' tail, $0.25 \mu \mathrm{M}$ of the reverse primer, $0.25 \mu \mathrm{M}$ of dyes and $2 \mu \mathrm{L}$ of genomic DNA $(15 \mathrm{ng} / \mu \mathrm{L})$. PCR amplifications were carried out under the following conditions: an initial denaturing step at $95^{\circ} \mathrm{C}$ for $5 \mathrm{~min}$, followed by 40 cycles of $95^{\circ} \mathrm{C}$ for $30 \mathrm{~s}$, annealing temperature for $30 \mathrm{~s}$ (Table Sl) and $72{ }^{\circ} \mathrm{C}$ for $30 \mathrm{~s}$, and a final elongation at $72{ }^{\circ} \mathrm{C}$ for 20 min. Two different simplex PCR plates, each with a different dye, were mixed and PCR product sizes were determined using a 3730XL DNA analyser (Applied Biosystems) and sized with a LIZ (500) standard using GeneMapper (Applied Biosystems).

For each locus, evidence for null alleles, large allele dropout and stutter peaks were examined using Micro Checker (Van Oosterhout et al. 2004). The test for link age disequilibrium among loci was conducted with GENEPOP (Rousset 2008) using a Benjamini and Yeku tieli correction (Benjamini \& Yekutieli 2001, Narum 2006). Diversity indices were calculated with GenAlex (Peakall \& Smouse 2012). Hardy Weinberg Equilibrium (HWE) was examined with GENEPOP (Rousset 2008) using an exact test with 100 batches and 1000 iterations per batch for each locus and a Chi square test for global HWE. Contemporary genetic effective population size $(\mathrm{Ne})$ was estimated using the VarEff $1.2 \mathrm{R}$ package (https://forge dga.jouy.inra.fr/). In addition, past changes in effective population size from microsatellite data (Nikolic \& Chevalet 2014) were estimated with the approximate likelihood Markov chain Monte Carlo (MCMC) approach in the VarEff $1.2 \mathrm{R}$ package (https://forge dga.jouy.inra.fr/). The mutation rate of microsatellite markers used in theVarEff $1.2 \mathrm{R}$ package was calculated according to the method of Storz and Beaumont (2002) implemented in the MSVAR 1.3 pro gram. The likelihood frequency of bottleneck events from the time to the most recent common ancestor (TMRCA) detected has been estimated with a new function source (BTLIKE, with free access and help sup port on the website https://forge dga.jouy.inra.fr/). Finally, we used Bottleneck 1.2.02 (Piry et al. 1999) to test for recent changes in $\mathrm{Ne}$ using three different tests based on expected heterozygosity excess: Wilcoxon sign rank test (two tailed for heterozygosity excess or defi ciency), sign test and standard difference test (100 000 iterations; Cornuet \& Luikart 1996), and under two mutation models: a two phase (TPM; non step wise $5 \%$, variance 12 ; typical values for many microsatellite markers; Busch et al. 2007) and a stepwise mutation model (SMM). 


\section{RESULTS}

Only one locus (Pseate 7805) had null alleles. Analyses were performed without this locus and these did not dif fer from analyses with all markers, so it was kept in this study. No large allele dropout and no stutter peaks were detected for any of the loci. No significant linkage dise quilibrium was observed among the loci $(P>0.05)$. The number of alleles per locus $(\mathrm{Na})$ ranged from 3 to 16 , with an average of 7.27 (Table 1). The mean number of effective alleles (Nef) (from Kimura \& Crow 1964) was 4.01 per locus and was always lower than $\mathrm{Na}$, highlight ing the presence of rare alleles. The observed $(\mathrm{Ho})$ and expected $(\mathrm{He})$ heterozygosities had means of 0.68 and 0.67, respectively. Ho reached 1 for locus Pseate 5563, which is $100 \%$ heterozygous for this locus. No signifi cant deviation from HWE was found in the population and the mean Fis was negative ( 0.051$)$ and non signifi cant $\left(\begin{array}{ll}P & 0.213\end{array}\right)$. With regard to loci, only locus Pse ate 7805 showed significant deviation from HWE (P 0.001).

The 15 microsatellite markers shared a similar range of mutation rate of around $3 \times 10^{-4}$ (sd 0.0004) with MSVAR estimates. The estimate of contemporary effec tive population size $(\mathrm{Ne})$ from 22 stranded individuals was 1211 individuals in harmonic mean $(95 \%$ confi dence interval (CI) 489 7999) from VarEff analysis. Estimates of the posterior distribution of past effective population sizes revealed a relatively large ancestral pop ulation size, three times larger than the current estimate (current theta index 4.405, past theta index 12.886). Analysis of the posterior distribution of the TMRCA showed a clear peak about 10000 genera tions ago and confirmed a decrease in population size in the past, with a smaller peak at about 500 generations (Figure S1). The two bottlenecks detected had high con fidence intervals of $94 \%$ but the beginning of the oldest peak interval (10 000 generations) was unclear due to the mixed signals of overlapping peaks. Bottleneck anal ysis based on expected heterozygosity excess also showed clear support for a recent population contrac tion. Both TMP and SSM models were consistent with the scenario of a bottleneck according to the results of Wilcoxon sign rank test, sign test and standard differ ence test (TPM: $P$ 0.041, 0.002 and 0.073 , respec tively; SMM: $P \quad 0.011,0.000$ and 0.030, respectively).

\section{DISCUSSION}

These results show the importance of understanding genetic diversity in rare and critically endangered spe cies. Indeed, our results suggest that an assumption of low genetic diversity in very rare species is not always supported and that conservation of the Mascarene Petrel may be successful despite a very small population size. It is interesting to note that Mascarene Petrels have a relatively high genetic diversity (highlighted by the anal ysis of $\mathrm{Na}$ and $\mathrm{Nef}$ values) for a rare and threatened spe cies that appears to have suffered a recent bottleneck (Ardern \& Lambert 1997, Spielman et al. 2004). Nef

Table 1. Results of initial microsatellite primer screening for Mascarene Petrels.

\begin{tabular}{|c|c|c|c|c|c|c|c|}
\hline Locus & $n$ & $\mathrm{Na}$ & Nef & Ho & $\mathrm{He}$ & Fis & HWE test \\
\hline Pseate 143 & 20 & 9 & 2.996 & 0.600 & 0.666 & 0.099 & 0.052 \\
\hline Pseate 255 & 22 & 8 & 5.469 & 0.864 & 0.817 & 0.057 & 0.647 \\
\hline Pseate 321 & 22 & 6 & 3.025 & 0.773 & 0.669 & 0.154 & 0.926 \\
\hline Pseate 1317 & 22 & 7 & 3.546 & 0.591 & 0.718 & 0.177 & 0.453 \\
\hline Pseate 1500 & 22 & 3 & 1.865 & 0.500 & 0.464 & 0.078 & 1.000 \\
\hline Pseate 1594 & 22 & 5 & 3.315 & 0.727 & 0.698 & 0.041 & 0.748 \\
\hline Pseate 1603 & 22 & 12 & 4.914 & 0.773 & 0.796 & 0.030 & 0.050 \\
\hline Pseate 1837 & 22 & 4 & 1.537 & 0.409 & 0.349 & 0.172 & 1.000 \\
\hline Pseate 3421 & 22 & 4 & 1.624 & 0.455 & 0.384 & 0.183 & 1.000 \\
\hline Pseate 3689 & 22 & 4 & 2.127 & 0.636 & 0.530 & 0.201 & 0.702 \\
\hline Pseate 5557 & 22 & 3 & 2.451 & 0.727 & 0.592 & 0.229 & 0.611 \\
\hline Pseate 5563 & 22 & 16 & 12.253 & 1.000 & 0.918 & 0.089 & 0.966 \\
\hline Pseate 7441 & 22 & 13 & 6.127 & 0.909 & 0.837 & 0.086 & 0.133 \\
\hline Pseate 7805 & 22 & 9 & 5.319 & 0.636 & 0.812 & 0.216 & 0.001 \\
\hline Pseate 8002 & 22 & 6 & 3.639 & 0.727 & 0.725 & 0.003 & 0.437 \\
\hline \multicolumn{8}{|l|}{ All loci } \\
\hline Mean & 21.867 & 7.267 & 4.014 & 0.688 & 0.665 & 0.051 & 0.213 \\
\hline se & 0.133 & 1.012 & 0.698 & 0.043 & 0.044 & 0.035 & -- \\
\hline
\end{tabular}

Fis coefficient of consanguinity (Wright 1931); He expected heterozygosity; Ho observed heterozygosity; $n$ number of individuals; $\mathrm{Na}$ total number of alleles per locus; Nef number of effective alleles per locus; HWE test $P$-values of the Hardy Weinberg equilibrium exact test (significant values in bold, $P<0.05$ ). 
values are also lower than $\mathrm{Na}$ values, which may suggest the presence of rare alleles in this population. Inbreeding and substructuring (Wahlund effect) have not been detected in the population, as indicated by the absence of a significant deviation from HWE (Wright 1969, Gar nier Géré \& Chikhi 2001).

Assuming an average generation length of 17.7 years for this species (Birdlife International 2018), the two peaks observed with the VarEff package would then indicate two population bottlenecks about 8850 and 177000 years ago. The first event was consistent with the tests for heterozygosity excess in the Bottleneck pro gram, which is detectable over a relative short period $2 \mathrm{Ne} 4 \mathrm{Ne}$ generations in the past (Cornuet \& Luikart 1996), and both analyses (VarEff package and Bottle neck) converged towards a reduction in population size.

Despite these findings, we interpret our results with caution because our sample size is small and estimates of the time of the demographic event could be more biased and subject to higher error than are estimates of Ne (Cabrera \& Palsbøll 2017). Cornuet et al. (2008) suggested that the poor estimation performance in time of the demographic event is caused by insufficient data. Moreover, the signal for a population decrease could also be due to population structure, which is known to generate spurious signals of bottlenecks (Nikolic \& Che valet 2014, Mazet et al. 2015). VarEff can be used to detect the effect of structure by varying the sampling strategy (Nikolic \& Chevalet 2014, Salmona et al. 2017) but we were limited in this study by the small number of individuals sampled.

High genetic diversity has already been observed in some vulnerable procellariiform species. Hale et al. (2015) reported high genetic diversity in two relict Hut ton's Shearwater Puffinus huttoni breeding populations. They found an average of 6.89 alleles/locus with an average $\mathrm{Ho}$ (observed heterozygosity) of 0.49 in the first population ( $n$ 39), and 7.33 alleles/locus with Ho 0.45 for the second population ( $n$ 30). Gravley et al. (2019) also found high genetic diversity in two subspecies of Northern Fulmar (Fulmarus glacialis rodger sii and Fulmarus glacialis auduboni). They found an aver age of 5.0 alleles/locus with an average $H o$ of 0.40 ( $n$ 39) for the first species (F. g. rodgersii), and an average of 6.1 alleles/locus with an average $H o$ of 0.45 for the second (F. g. auduboni) (n 30). Loss of genetic diversity should occur whenever a population goes through a bottleneck (Nei et al. 1975) and relatively high genetic diversity in a rare species can indicate that decline in population size is recent (Moritz 2002).

Population contraction over a large number of gener ations may be required for loss of genetic diversity but this effect could be influenced by a species' life history traits, such as long generation times, delayed sexual maturity and/or the rate of demographic fluctuation (Kuo \& Janzen 2004). This phenomenon has been observed in other bottlenecked populations (Hailer et al. 2006, Pickles et al. 2012) and supports the hypothesis that monogamy and long generation time could slow genetic diversity loss after the detected bottleneck in the Mascarene Petrel population. For example, Hailer et al. (2006) argue that the long generation time of White tailed Eagles Haliaeetus albicilla has acted as an intrinsic buffer against loss of genetic diversity in a bottlenecked population. Weiser et al. (2013) compared the loss of genetic diversity following a bottleneck in three species with different life history traits (monogamous/polyga mous, long/short generation time); they showed that a monogamous species with a long generation time had the highest probability of retaining rare alleles without immigration in the population. Furthermore, Milot et al. (2007) simulations on Wandering and Amsterdam alba trosses (Diomedea exulans and Diomedea amsterdamen sis), which have respectively a large and small population size, support the hypothesis that genetic diversity in these two long lived species was already depleted prior to their divergence. Amsterdam Albatross would be able to maintain its genetic variation over a very long period of time, due to its life history traits: long life span, high reproductive success, inbreeding avoidance behaviours (e.g. Amos \& Balmford 2001) and odour based individual recognition (e.g. Bonadona \& Nevitt 2004). Although there are some limitations in comparing genetic diversity across microsatellite studies, our study adds to a body of work that suggests that long lived species may be able to maintain their genetic variability, a key factor enabling survival of a natural population (Frankham 2005).

Our results suggest that there is still high genetic diversity in the Mascarene Petrel, supporting the argu ment that conservation efforts are not too late for this species. Further studies of diversity and genetic structur ing, associated with other markers such as single nucleotide polymorphisms (SNPs), and of additional individuals sampled from the newly discovered breeding sites could help to better understand this species and contribute to more informed conservation planning.

This study is a production of the European project LIFE + Petrels (grant number: LIFE13 BIO/FR/000075) co led by Le Parc national de La Réunion, l'Université de La Réunion, La Société d'Etudes Ornithologiques de La Réunion (SEOR) and l'Office National de la Chasse et de la Faune Sauvage, with financial support from the European Union, La Direction de l'Environnement l'Aménagement et du Logement (DEAL) and Le Conseil Départemental of Reunion Island. We thank all of the people who have participated in the SEOR rescue cam paign of Mascarene Petrels, especially Fabien Jan, Julie Tour metz and Samantha Renault. Thanks to M. Goron, M. Manoury and D. Da Silva for their help in the laboratory. We are very grateful to Claude Chevalet for improving the VarEff package and allowing us to calculate confidence intervals around detected bottlenecks. We also thank P. Hodum for 
improving the English text. We thank Genoscreen GmbH (Zur ich, Switzerland) for the development of microsatellite markers and the Gentyane platform (Clermont Ferrand, France) for determination of the PCR product sizes. Finally, we are grateful for the efforts of the reviewers to improve the manuscript.

\section{AUTHOR CONTRIBUTION}

Jade Lopez: Formal analysis (equal); Investigation (equal); Validation (equal); Visualization (equal); Writ ing original draft (equal); Writing review \& editing (equal). Natacha Nikolic: Formal analysis (equal); Inves tigation (equal); Methodology (equal); Software (equal); Validation (equal); Visualization (equal); Writing review \& editing (equal). Martin Riethmuller: Resources (equal). Jerome Dubos: Resources (equal); Writing re view \& editing (equal). Patrick Pinet: Funding acquisi tion (equal); Project administration (equal); Supervision (equal); Writing review \& editing (equal). Patxi Souharce: Resources (equal). François-Xavier Couzi: Resources (equal). Matthieu Le Corre: Conceptualiza tion (equal); Funding acquisition (equal); Investigation (equal); Project administration (equal); Supervision (equal); Validation (equal); Writing original draft (equal); Writing review \& editing (equal). Audrey Jaeger: Investigation (equal); Supervision (equal); Valida tion (equal); Writing original draft (equal); Writing review \& editing (equal). Laurence Humeau: Conceptu alization (equal); Formal analysis (equal); Investigation (equal); Methodology (equal); Project administration (equal); Supervision (equal); Validation (equal); Visual ization (equal); Writing original draft (equal); Writing review \& editing (equal).

\section{DATA AVAILABILITY STATEMENT}

The data that support the findings of this study are pre sent in Table S2; genotype of the 22 individuals of Mas carene Petrel (Pseudobulweria aterrima) for the 15 microsatellite markers used.

\section{REFERENCES}

Amos, W. \& Balmford, A. 2001. When does conservation genetics matter? Heredity 87: 257.

Ardern, S.L. \& Lambert, D.M. 1997. Is the Black Robin in genetic peril? Mol. Ecol. 6: 2128.

Benjamini, Y. \& Yekutieli, D. 2001. The control of the false discovery rate in multiple testing under dependency. Ann. Stat. 29: 11651188.

BirdLife International (2018). Pseudobulweria aterrima. The IUCN Red List of Threatened Species 2018: e.T22697896A132611797. 2018, https://doi.org/10.2305/ IUCN.UK.2018-2.RLTS.T22697896A132611797.en (accessed 10 December).

Bonadonna, F. \& Nevitt, G.A. 2004. Partner-specific odor recognition in an Antarctic seabird. Science 306: 835.
Busch, J.D., Waser, P.M. \& DeWoody, J.A. 2007. Recent demographic bottlenecks are not accompanied by a genetic signature in banner-tailed kangaroo rats (Dipodomys spectabilis). Mol. Ecol. 16: 24502462.

Cabrera, A.A. \& Palsbøll, P.J. 2017. Inferring past demographic changes from contemporary genetic data: a simulation-based evaluation of the $A B C$ methods implemented in DIYABC. Mol. Ecol. Resour. 17: 94110.

Cornuet, J.M. \& Luikart, G. 1996. Description and power analysis of two tests for detecting recent population bottlenecks from allele frequency data. Genetics 144: 20012014.

Cornuet, J.M., Santos, F., Beaumont, M.A., Robert, C.P., Marin, J.M., Balding, D.J. \& Estoup, A. 2008. Inferring population history with DIY ABC: A user-friendly approach to approximate Bayesian computation. Bioinformatics 24: 27132719.

Croxall, J.P., Butchart, S.H., Lascelles, B.E.N., Stattersfield, A.J., Sullivan, B.E.N., Symes, A. \& Taylor, P.H.I.L. 2012. Seabird conservation status, threats and priority actions: a global assessment. Bird Conserv. Int. 22: 134.

Dias, M.P., Martin, R., Pearmain, E.J., Burfield, I.J., Small, C., Phillips, R.A., Yates, O., Lascelles, B., Borboroglu, P. \& Croxall, J.P. 2019. Threats to seabirds: a global assessment. Biol. Conserv. 237: 525537.

Frankel, O. \& Soulé, M.E. 1981. Conservation and evolution. Cambridge: CUP Archive.

Frankham, R. 2005. Genetics and extinction. Biol. Conserv. 126: 131140.

Frankham, R., Briscoe, D.A. \& Ballou, J.D. 2002 Introduction to conservation genetics. Cambridge: Cambridge University Press.

Garnier-Géré, P. \& Chikhi, L. 2001. Population subdivision, Hardy-Weinberg equilibrium and the Wahlund effect. eLS.

Gooley, R.M., Hogg, C.J., Belov, K. \& Grueber, C.E. 2018. The effects of group versus intensive housing on the retention of genetic diversity in insurance populations. BMC Zool. 3: 2.

Gravley, M.C., Sage, G.K., Ramey, A.M., Hatch, S.A., Gill, V.A., Rearick-Whitney, J.R., Talbot, S.L. 2019. Development and characterization of polymorphic microsatellite markers in northern fulmar, Fulmarus glacialis (Procellariiformes), and cross-species amplification in eight other seabirds. Genes. Genom., 41(9): 10151026.

Hailer, F., Helander, B., Folkestad, A.O., Ganusevich, S.A., Garstad, S., Hauff, P., Ellegren, H. 2006. Bottlenecked but long-lived: high genetic diversity retained in white-tailed eagles upon recovery from population decline. Biol. Lett. 2: 316319

Hale, M., Harro, G., Bradfield, P. \& Holdaway, R.N. 2015. Genetic similarity of Hutton's shearwaters (Puffinus huttoni) from two relict breeding populations. Notornis 62: 130134 .

Keitt, B.S., Wilcox, C., Tershy, B.R., Croll, D.A. \& Donlan, C.J. 2002. The effect of feral cats on the population viability of black-vented shearwaters (Puffinus opisthomelas) on Natividad Island, Mexico. Anim. Conserv. 5: 217223.

Kimura, M. \& Crow, J.F. 1964. The number of alleles that can be maintained in a finite population. Genetics 49: 725 .

Kuo, C.H. \& Janzen, F.J. 2004. Genetic effects of a persistent bottleneck on a natural population of ornate box turtles (Terrapene ornata). Conserv. Genet. 5: 425437. 
Lande, R. 1995. Mutation and conservation. Conserv. Biol. 9: 782791.

Le Corre, M. 2008. Conservation biology: cats, rats and seabirds. Nature 451: 134.

Le Corre, M., Ghestemme, T., Salamolard, M. \& Couzi, F.-X. 2003. Rescue of the Mascarene Petrel, a critically endangered seabird of Réunion Island, Indian Ocean. Condor 105: 391395.

Lippe, C., Dumont, P. \& Bernatchez, L. 2006. High genetic diversity and no inbreeding in the endangered copper redhorse, Moxostoma hubbsi (Catostomidae, Pisces): the positive sides of a long generation time. Mol. Ecol. 15: 17691780.

Lynch, M. \& Gabriel, W. 1990. Mutation load and the survival of small populations. Evolution 44: 17251737.

Lynch, M. \& Lande, R. 1998. The critical effective size for a genetically secure population. Anim. Conserv. 1: 7072 .

Masel, J. 2012. Rethinking Hardy Weinberg and genetic drift in undergraduate biology. BioEssays 34: 701710.

Mazet, O., Rodríguez, W. \& Chikhi, L. 2015. Demographic inference using genetic data from a single individual: separating population size variation from population structure. Theoret. Popul. Biology. 104: 4658.

Milot, E., Weimerskirch, H., Duchesne, P. \& Bernatchez, L. 2007. Surviving with low genetic diversity: the case of albatrosses. Proc. Biol. Sci. 274: 779787.

Moritz, C. 2002. Strategies to protect biological diversity and the evolutionary processes that sustain it. Syst. Biol. 51: 238254.

Narum, S.R. 2006. Beyond Bonferroni: less conservative analyses for conservation genetics. Conserv. Genet. 7: 783 787.

Nei, M., Maruyama, T. \& Chakraborty, R. 1975. The bottleneck effect and genetic variability in populations. Evolution 29: 110

Nikolic, N. \& Chevalet, C. 2014. Detecting past changes of effective population size. Evol. Appl. 7: 663681.

Peakall, R.O.D. \& Smouse, P.E. 2012. GenAlex 6.5: genetic analysis in Excel. Population genetic software for teaching and research-an update. Bioinformatics 28: 25372539.

Pickles, R.S.A., Groombridge, J.J., Rojas, V.Z., Van Damme, P., Gottelli, D., Ariani, C.V. \& Jordan, W.C. 2012. Genetic diversity and population structure in the endangered giant otter Pteronura brasiliensis. Conserv. Genet. 13: 235 245.

Piry, S., Luikart, G. \& Cornuet, J.M. 1999. BOTTLENECK: a computer program for detecting recent reductions in the effective population size using allele frequency data. $\mathrm{J}$. Hered. 90: 502503.

Rodríguez, A., Holmes, N.D., Ryan, P.G., Wilson, K.J., Faulquier, L., Murillo, Y., Negro, J.J. 2017. Seabird mortality induced by land-based artificial lights. Conserv. Biol. 31: 9861001.

Rousset, F. 2008. genepop'007: a complete reimplementation of the genepop software for Windows and Linux. Mol. Ecol. Resour. 8: 103106.
Salmona, J., Heller, R., Quéméré, E. \& Chikhi, L. 2017. Climate change and human colonization triggered habitat loss and fragmentation in Madagascar. Mol. Ecol. 26: 120.

Schreiber, E.A. \& Burger, J. (eds) 2001. Biology of marine birds. Boca Raton, FL: CRC Press.

Schuelke, M. 2000. An economic method for the fluorescent labeling of PCR fragments. Nat. Biotechnol. 18: 233.

Spielman, D., Brook, B.W., Briscoe, D.A. \& Frankham, R. 2004. Does inbreeding and loss of genetic diversity decrease disease resistance? Conserv. Genet. 5: 439448.

Storz, J.F. \& Beaumont, M.A. 2002. Testing for genetic evidence of population expansion and contraction: an empirical analysis of microsatellite DNA variation using a hierarchical Bayesian model. Evolution 56: 154166.

Van Oosterhout, C., Hutchinson, W.F., Wills, D.P. \& Shipley, P. 2004. MICRO-CHECKER: software for identifying and correcting genotyping errors in microsatellite data. Mol. Ecol. Notes 4: 535538.

Warham, J. 1990. The petrels: their ecology and breeding systems. London: A\&C Black.

Weiser, E.L., Grueber, C.E. \& Jamieson, I.G. 2013. Simulating retention of rare alleles in small populations to assess management options for species with different life histories. Conserv. Biol. 27: 335344.

Wright, S. 1969. Evolution and the Genetics of Populations: Vol. 2. The Theory of Gene Frequencies. Chicago, IL: University of Chicago Press.

Wright, S. (1931) Evolution in Mendelian populations. Genetics, 16(2): 97.

\section{SUPPORTING INFORMATION}

Additional supporting information may be found online in the Supporting Information section at the end of the article.

Data S1. Methods for the development of the microsatellite markers by Ecogenics GmbH (Zurich, Switzerland).

Table S1. Characteristics of 15 microsatellite markers developed for Mascarene Petrels. Annealing temperature (Ta).

Table S2. Genotype of the 22 individuals of Mas carene Petrel (Pseudobulweria aterrima) for the 15 microsatellite markers used.

Figure S1. Posterior distribution of the time to most recent common ancestor allele (TMRCA). Each peak represents a potential bottleneck. 